\title{
Performance Evaluation on Over-Saturated Brine Cement Slurry of Anhydrite Formation
}

\author{
Lin $\mathrm{Xu}^{1, \text { a }}$, Mingbiao $\mathrm{Xu}^{2, \mathrm{~b}, *}$, Xiaoliang $\mathrm{Wang}^{3, \mathrm{c}}$ \\ ${ }^{1}$ College of Petrochemical and Energetic Engineering, Zhejiang Ocean University, Zhoushan \\ 316022, China \\ ${ }^{2}$ Hubei Collaborative Innovation Center for Unconventional Oil and Gas, Wuhan 430100, China \\ ${ }^{3}$ Jiahua Technology Co., Ltd, Jingzhou 434000, China \\ aemail: xuhu_11@yeah.net, ${ }^{b}$ email:xmb62@163.com, cemail:13972384660@163.com \\ ${ }^{*}$ Corresponding author
}

\begin{abstract}
Keywords: Over-Saturated brine; Cement slurry; Anhydrite formation; Oil field production
Abstract. The anhydrite formation has a highly negative impact on the stability of cement slurry, which can cause failure of cementing operation upon well construction. In combination to anhydrite characteristics of Missan Oilfields, herein, a new type of over-saturated brine cement slurry was established. The density of cement slurry was design to be as high as $2.30 \mathrm{~g} / \mathrm{cm}^{3}$, in order to eliminate the potential plastic deformation of anhydrite formation. The formula of cement slurry was systematically optimized by evaluating the applied performance in the considered content range of additives, using the one-factor method. The results showed that, the over-saturated brine cement slurry designed here exhibits excellent and robust property such as those of thickening, compressive strength, fluid loss, and rheology, which can not only meet the cementing requirements on-site, but also supply key information and technology support for development of cement slurry family.
\end{abstract}

\section{Introduction}

An appropriate type of cement slurry is always fundamental for the petroleum well construction, through which the sustainable, safe and economic production of oil $\&$ gas can be fulfilled. Anhydrite cementing remains a key obstacle to sustaining operational success in well construction, due to specific structure of anhydrite formation. follows:

In the oilfield production, anhydrite formation has various disadvantages ${ }^{[1-3]}$, as described as

- Plastic deformation and cramp of salt formations;

- Mirabilite and gypsum swelling;

- Collapse of anhydrite formations;

- Instable shale;

- Abnormal pressures;

- Recrystallization upon fluid returning.

Some accidents of well construction such as the hole shrinkage, pear-shaped profile, case deformation, and even hole collapse, that are closely related with these disadvantages described above, have been extensively reported ${ }^{[4,5]}$. Using the appropriate cement slurry, these production accidents can be effectively avoided in the anhydrite reservoir.

Despite a wide range of investigation on cement slurry systems available in the anhydrite formation, the general results achieved from previous work appear to be relatively limited to reserve in a certain environment. That is, when the formation environment varies, the cement slurry needs to be specifically made in terms of the corresponding downhole condition, in order to meet cementing requirements. This strategy makes it possible to tackle potential cementing problems.

In Missan Oilfields, a huge anhydrite formation(up to $500 \mathrm{~m}$ ) was found at the depth of about 2,000m, and some typical accidents like cementing failure and pipe sticking were often encountered, which markedly limited production of Missan Oilfields. Therefore, it is necessary to develop an appropriate type of cement slurry based on the on-site downhole data, for the purpose of ensuring rehabilitation of oilfields. In this present work, we have carried out a series of tests to establish a kind of 
over-saturated brine cement slurry with a high density, on the basis of downhole environment of Missan Oilfields.

\section{Methodology}

Experimental materials The over-saturated brine cement slurry was constructed with 9 functional additives, such as weighting agent, filtrate loss reducer(LATEX), expanding agent(EX), High temperature(HT) strength stabilizer(SP), dispersant, defoamer, and retarder(H63L). Using these materials, cement slurry was prepared in terms of the standard API method. Note that, the application performance is mostly dependent on the weighting material, filtrate loss reducer, propping agent, strength stabilizer, and retarder, all of which were further evaluated for optimizing slurry formula.

Tests of applied performance General applied performance of cement slurry contains those of rheology, filtrate loss, compressive strength, and thickening. Rheological data of the designed cement slurry was measured at six specific shear rates of $600,300,200,100,6$, and 3rpm with a Fann 35 viscometer. Filtration tests were performed on the cement slurry at $6.9 \mathrm{MPa}$ and considered temperature by a HTHP filter tester. The thickening data were measured under the designed conditions with a HTHP thickening apparatus.

Experimental Design With the selected functional additives, the formula of over-saturated brine cement slurry was preliminarily established in early work. The basic formula of cement slurry is as follows: $\mathrm{G}$ class cement + fresh water + brine $(\mathrm{NaCl})+\mathrm{LATEX}+\mathrm{SP}+\mathrm{H} 63 \mathrm{~L}+\mathrm{EX}+$ weighting agent + dispersant + propping agent + defoamer.

Herein, a set of one-factor experiments were designed to evaluate the performance of cement slurry by optimizing contents of additives. The key additives such as LATEX, SP, H63L, and brine were typically investigated in the considered content range. It should be pointed out that unless otherwise specified, all thickening tests were carried out at $120^{\circ} \mathrm{C} / 110 \mathrm{MPa}$ and compressive strength tests were performed at $120^{\circ} \mathrm{C}$.

\section{Results and discussion}

Analysis on salt content $\mathrm{NaCl}$ was added to the cement slurry to adjust density of continuous phase and construct over-saturated brine solution. It is well known that salt content is closely associated with applied performance, especially the thickening property. To optimize the content of $\mathrm{NaCl}$, herein, the applied performance of cement slurry was tested in the content range of $0 \sim 60 \mathrm{wt} \%$. It should be noted that, $\mathrm{NaCl}$ content is added and defined with respect to fresh water addition in the cement slurry.
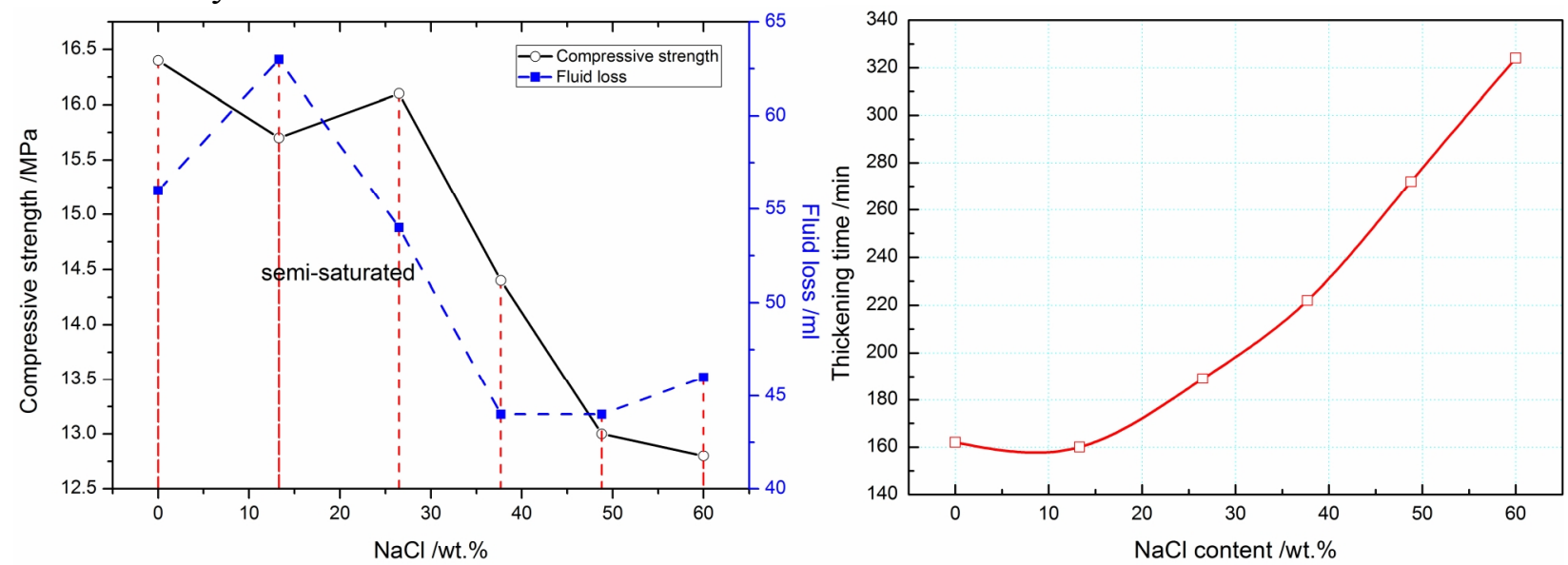

Figure 1 left: relation between content of $\mathrm{NaCl}$ and compressive strength and fluid loss; right: curve of content of LATEX vs. thickening time.

In Figure 1, one can observe that with increasing $\mathrm{NaCl}$ content, both compressive strength and fluid loss value decrease, but a reverse trend is found for the thickening property. That is, the larger $\mathrm{NaCl}$ content, the longer the thickening time is. In particular, thickening time rapidly rises while the $\mathrm{NaCl}$ content exceeds 50wt.\%, displaying a strong retard property at the high $\mathrm{NaCl}$ content. This 
phenomenon is mainly attributed to weak hydration of cement caused by the high content of $\mathrm{NaCl}$. In general, the thickening property is closely associated with the compressive strength of cement slurry. The longer the thickening time, the weaker the compressive strength becomes. Accordingly, it is clear that compressive strength decreases with increment of $\mathrm{NaCl}$ content.

Table 1 Rheological readings of the cement slurry at different $\mathrm{NaCl}$ addition

\begin{tabular}{|c|c|c|c|}
\hline \multirow{2}{*}{$\begin{array}{c}\text { NaCl content } \\
(\text { wt. } \%)\end{array}$} & \multicolumn{3}{|c|}{ Rheological characteristic readings } \\
\cline { 2 - 4 } & $\theta_{600} / \theta_{300}$ & $\theta_{200} / \theta_{100}$ & $\theta_{6} / \theta_{3}$ \\
\hline 0 & $-/-$ & $246 / 150$ & $16 / 12$ \\
\hline 13 & $-/ 200$ & $149 / 84$ & $9 / 5$ \\
\hline 26 & $242 / 138$ & $99 / 54$ & $5 / 3$ \\
\hline 38 & $245 / 140$ & $101 / 56$ & $5 / 3$ \\
\hline 49 & $225 / 126$ & $91 / 50$ & $5 / 3$ \\
\hline 61 & $230 / 129$ & $92 / 50$ & $5 / 3$ \\
\hline
\end{tabular}

Rheological characteristic readings obtained by six-speed viscometer are listed in Table 1 . The rheological readings decrease with a rise of $\mathrm{NaCl}$ content, which reflects that $\mathrm{NaCl}$ has a dilute effect on the cement slurry. Without $\mathrm{NaCl}$, for instance, the $\theta_{600}$ and $\theta_{300}$ readings of the slurry exceeds the measuring range of viscometer; while $\mathrm{NaCl}$ content is $49 \mathrm{wt} . \%, \theta_{600}$ and $\theta_{300}$ are 225 and 126 , respectively. What's more, a comparison of reading of the low shear rate shows that $\theta_{6}$ and $\theta_{3}$ values at $49 \mathrm{wt} . \%$ decrease by $69 \%$ and $75 \%$, respectively, than that without $\mathrm{NaCl}$. These results show that in over-saturated brine system, the role played by $\mathrm{NaCl}$ is important to improve the comprehensive performance of slurry. To construct over-saturated system, the Nacl content is determined to be 49 wt. $\%$.

Analysis on content of filtrate loss reducer As one kind of liquid filtration loss reducer, LATEX contains about $50 \mathrm{wt}$ \% colloidal particles with a size of $0.05 \sim 0.5 \mathrm{um}$, which can fill the filter cake to reduce its permeability. To optimize the content of LATEX, the applied performance of cement slurry concerning thickening, compressive strength, filtration, and rheology, was tested in the content range of $0 \sim 7.5 \mathrm{wt} . \%$ (see Figure 2). The relation between LATEX contents and fluid loss, compressive strength, and thickening time were presented in Figure 2.
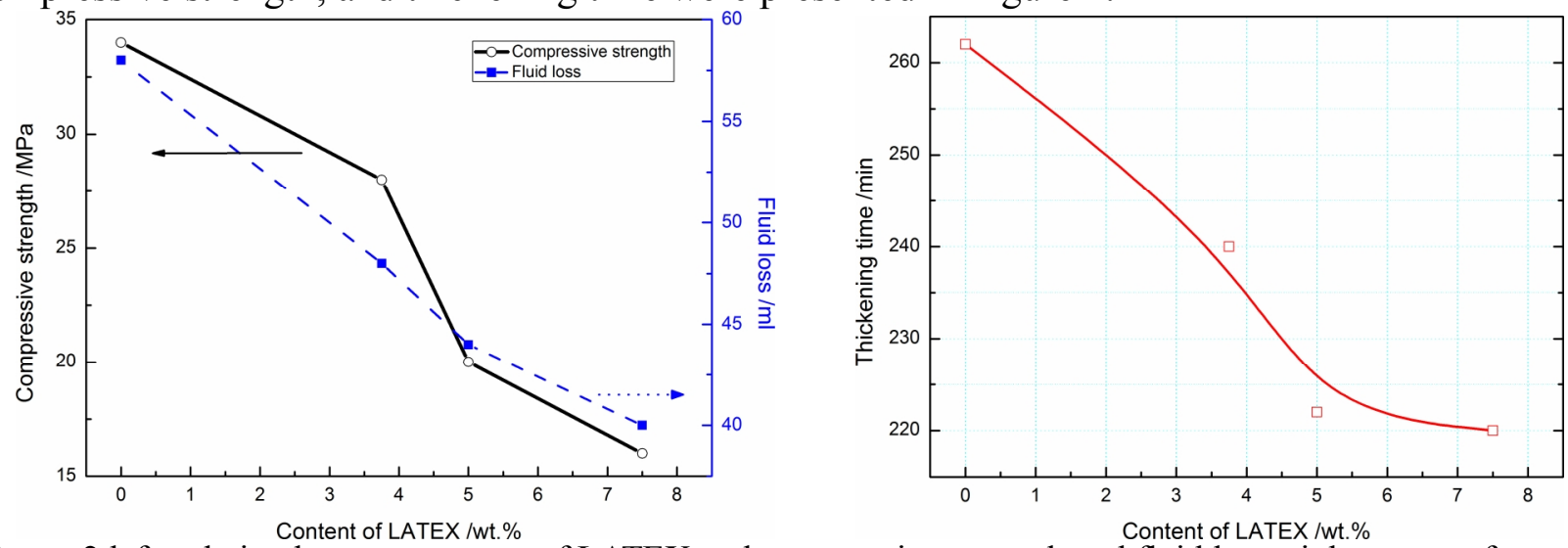

Figure 2 left: relation between content of LATEX and compressive strength and fluid loss; right: curve of content of LATEX vs. thickening time.

It is clear in Figure 2 that all of the tested data involving the compressive strength, fluid loss, and thickening time decline with a rise of LATEX content, wherein fluid loss exhibits a larger decrease. For example, the fluid loss has a decrease up to $31 \%$, while LATEX content increases to $7.5 \mathrm{wt} \%$. This result discloses that LATEX performs well as filtrate reducer in the slurry. Due to the special liquid state, LATEX can penetrate the deep formation and form an effective block to prevent fluid loss. 
Table 2 Rheological readings of the cement slurry at different LATEX content

\begin{tabular}{|c|c|c|c|}
\hline \multirow{2}{*}{$\begin{array}{c}\text { LATEX content } \\
(\text { wt.\%) }\end{array}$} & \multicolumn{3}{|c|}{ Rheological readings } \\
\cline { 2 - 4 } & $\theta_{600} / \theta_{300}$ & $\theta_{200} / \theta_{100}$ & $\theta_{6} / \theta_{3}$ \\
\hline 0 & $190 / 101$ & $72 / 39$ & $5 / 3$ \\
\hline 3.75 & $225 / 129$ & $92 / 50$ & $5 / 3$ \\
\hline 5 & $245 / 140$ & $101 / 56$ & $5 / 3$ \\
\hline 7.5 & $255 / 147$ & $107 / 60$ & $6 / 4$ \\
\hline
\end{tabular}

Further, Table 2 lists the rheological parameter for the slurry in the considered LATEX content. One can find that in the investigated contents, all rheological readings slightly increase, suggesting that LATEX has a little impact on the slurry rheology. On the basis of the results obtained above, the LATEX content is proposed to be $5 \mathrm{wt} . \%$.

Analysis on content of HT strength stabilizer SP was selected as the strength agent to improve the HT strength of the final cement stone. To optimize SP dosage, herein, the applied performance of cement slurry was tested while varying SP contents in the range of $20 \sim 40 \mathrm{wt} . \%$. Due to a weak impact of SP on viscosity and filtration of the slurry, much attention is paid to the compressive strength upon optimization tests. Note that, to emphasize HT strength of the cement slurry, the thickening tests were carried out at $130^{\circ} \mathrm{C} / 110 \mathrm{MPa}$ and compressive strength tests were performed at $150^{\circ} \mathrm{C}$. The relation between SP content and compressive strength is presented in Figure 3.

As can be seen in Figure 3, the thickening time reduces and compressive strength rises with increasing SP contents. In particular, thickening time has a dramatic decrease when SP content is more than $35 \mathrm{wt} . \%$, suggesting that the compressive strength reinforce significantly, which is well consistent with trend of compressive strength. Such reinforcing behavior of SP can be rationalized by a special match of particle size. That is to say, SP involving a special range of particle size(about 300mesh) can cooperatively work with cement particle to significantly improve compressive strength of cement stone. Using this approach, the filtration of slurry can also be effectively reduced. It is worthy of noting that SP content is proposed to be $49 \mathrm{wt} . \%$, coupled with conclusions of the compressive strength and thickening tests.
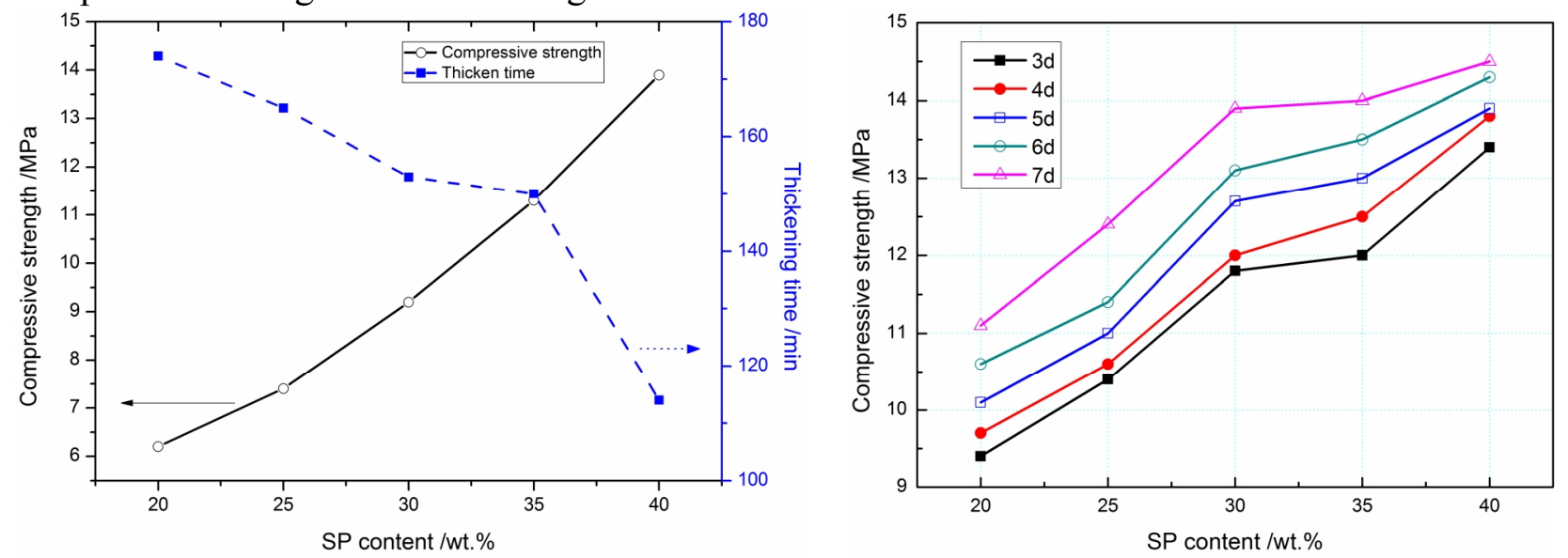

Figure 3 left: relation between SP content and compressive strength and thickening time;

\section{Conclusions}

A set of performance tests was conducted on the over-saturated brine cement slurry of anhydrite formation, to evaluate the role played by the involved key additives, for the purpose of improving performance of slurry. The results derived from the designed tests showed that the over-saturated brine cement slurry with a high density of $2.3 \mathrm{~g} / \mathrm{ml}$ exhibits good thickening property, rheology, and compressive strength, which not only meet the cementing requirements on-site, but also will be helpful for rehabilitation of Missan oilfields. 


\section{Acknowledgements}

This work was financially supported by the National Key Scientific and Technological Project(No. 2011ZX05017-002-HZ07) and Scientific Research Foundation of Zhejiang Ocean University (Project No. Q1510).

\section{References}

[1] Q.Y Liu, Y. Wang, L.Fan, L.P. Liu, Y. H. Deng and X. Liu: Drilling Fluid \& Completion Fluid, Vol.22 (2002), p. 59

[2] Z.F. Huang, X.J. Chen and Y. Liu: Sino-Global Energy, Vol.12 (2007), p.56

[3] L.Y. Chang, Y. Gao, J.H. Xu and G.G. Yang: Oil Drilling \& Production Technology, Vol.35 (2013), p.35

[4] X.C. Wang, X. Nan and J. Chen: Xinjiang Oil \& Gas, Vol.2 (2015), p. 33

[5] N. Zhen, L. He, J.L. Zou, Z.Y. Zhang and Y.F. Chen: SPE Conference, SPE-176203-MS (2015) 